Article

\title{
Immobilization of Detonation Nanodiamonds on Macroscopic Surfaces
}

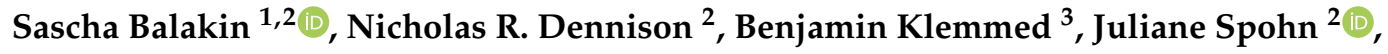 \\ Gianaurelio Cuniberti ${ }^{1,4,5}$, Lotta Römhildt ${ }^{2}$ and Jörg Opitz ${ }^{1,2, *}$ \\ 1 Institute for Materials Science and Max Bergmann Center of Biomaterials, Technische Universität Dresden, \\ 01062 Dresden, Germany; sascha.balakin@ikts-extern.fraunhofer.de (S.B.); \\ gianaurelio.cuniberti@tu-dresden.de (G.C.) \\ 2 Fraunhofer Institute for Ceramic Technologies and Systems IKTS Material Diagnostics, \\ 01109 Dresden and 04103 Leipzig, Germany; dennison.nd@gmail.com (N.R.D.); \\ juliane.spohn@ikts.fraunhofer.de (J.S.); lotta.lkr@gmail.com (L.R.) \\ 3 Physical Chemistry, Technische Universität Dresden, 01062 Dresden, Germany; \\ benjamin.klemmed@chemie.tu-dresden.de \\ 4 Dresden Center for Computational Materials Science, Technische Universität Dresden, \\ 01062 Dresden, Germany \\ 5 Center for Advancing Electronics Dresden, Technische Universität Dresden, 01062 Dresden, Germany \\ * Correspondence: Joerg.opitz@ikts.fraunhofer.de
}

Received: 31 January 2019; Accepted: 5 March 2019; Published: 13 March 2019

check for updates

\begin{abstract}
Detonation nanodiamonds (NDs) are a novel class of carbon-based nanomaterials, and have received a great deal of attention in biomedical applications, due to their high biocompatibility, facile surface functionalization, and commercialized synthetic fabrication. We were able to transfer the NDs from large-size agglomerate suspensions to homogenous coatings. ND suspensions have been used in various techniques to coat on commercially available substrates of pure Ti and $\mathrm{Si}$. Scanning electron microscopy (SEM) imaging and nanoindentation show that the densest and strongest coating of NDs was generated when using 1-ethyl-3-(3-dimethylaminopropyl)carbodiimide and N-hydroxysuccinimide (EDC/NHS)-mediated coupling to macroscopic silanized surfaces. In the next step, the feasibility of DNA-mediated coupling of NDs on macroscopic surfaces is discussed using fluorescent microscopy and additional particle size distribution, as well as zeta potential measurements. This work compares different ND coating strategies and describes the straightforward technique of grafting single-stranded DNA onto carboxylated NDs via thioester bridges.
\end{abstract}

Keywords: detonation nanodiamonds; bio-conjugation; de-agglomeration; fluorescent microscopy; nanoindentation

\section{Introduction}

Titanium and titanium-based alloys have been used as implant material for a long time, due to their high ratio of tensile strength and Young's Modulus $(\sigma \mathrm{U} / \mathrm{E})$, excellent corrosion properties, and high biocompatibility, respectively [1]. The rate and quality of osseointegration in Ti implants are strongly related to their surface properties. Surface composition, hydrophilicity, and roughness are parameters that play a significant role in implant-tissue interaction and osseointegration [2,3]. However, $\mathrm{Ti}$ and its alloys cannot meet all of the clinical requirements. Therefore, in order to improve the biological, chemical, and mechanical properties, surface modification is often performed [4], using anodic oxidation [5], calcium phosphate/hydroxyapatite [6], bioactive glasses [7], diamond-like carbon (DLC) [8], and microwave plasma chemical vapor deposition (MPCVD) of nanodiamond films [9]. MPCVD nanodiamond films possess biocompatibility and chemical 
inertness [10], but these techniques require specialized and expensive equipment compared to wet-chemical detonation nanodiamond (ND) coatings [11]. In order to enhance the osseointegration of oral Ti implants, some implant systems have surface nanostructures and bioactive ion chemistry (calcium, fluoride, or strontium [12]), or nanometer-sized calcium phosphate coatings, which are currently in clinical use [13-15]. Nevertheless, it is difficult to draw conclusions about which surface factor (i.e., nanotopography or surface ion chemistry) plays the more dominant role in implant osseointegration [16]. It has been reported that the bone cells are accustomed to a nanoscale environment rather than to a microscale environment [17]. For instance, osteoblasts were found to proliferate more quickly on nanostructured alumina and hydroxyapatite than on conventional counterparts [18]. At the same time, increasing attention is being given to prospects in medical and biological applications of NDs, due to their nontoxicity, as well as their structural, surface, and spectroscopic properties [19,20]. ND research has extended into the biomedical field, with recent in vitro and in vivo animal studies that demonstrate that NDs are biocompatible and non-toxic, even to human cells [21]. Biofunctional NDs are used to prevent secondary tumour formation in mice [22], and NDs show full clearance in mice after 10 days [23]. Novel in vitro studies have demonstrated the absence of cytotoxicity in NDs [24], suggesting the use of NDs as biolabels [25] and drug delivery vehicles [26]. Moreover, protein-functionalized NDs are nontoxic and can enter mammalian cells efficiently [27]. In-vivo studies have included oral, subcutaneous, intramuscular, and intravenous administration of sterile ND hydrosols [28]. It is feasible to link NDs to actin filaments [29] or glycoproteins [30], so the variety of possibilities to conjugate NDs is great [31]. The study of ND effects on the growth and development of chicken embryos found that NDs may reduce blood vessel formation and affect the development of the circulatory system by inhibiting proangiogenic factor bFGF (basic fibroblast growth factor) [32]. Thomas et al. showed that macrophage cell proliferation and metabolic activity were significantly reduced in the presence of ND wear debris. In contrast, ND exposure significantly reduced the expression of several genes that play key roles in inflammation and related bone loss, including tumour necrosis factor and platelet derived growth factor [33]. Oxygen-terminated NDs immobilized on glass have shown a confluent cellular attachment of human neural stem cells, and enhanced cell adhesion compared to bare glass [34]. Monolayers of NDs universally promote murine hippocampal neuronal adhesion, wherein smaller-sized NDs promote greater neurite extension [35]. Huang et al. showed the high biocompatibility of immobilized NDs using layer-by-layer deposition of poly-L-lysine and ND-drug conjugates [36].

The above investigations prove the feasibility of ND coatings for biomedical applications. In this work, a new ND-based coating for Ti and Si surfaces will be investigated. The opportunities of NDs will be considered in respect to as-received and silanized surfaces, as well as DNA-mediated immobilization strategies. The possible application combines the high potential of bio-functionalisation with the structural improvements and excellent drug-delivery-platform properties of NDs. The task of the present work is to study the immobilization strategies, the colloidal stability, and the coating behaviour of ND suspensions. In order to achieve a homogenous layer of NDs on different kinds of substrates, dip coating and electrophoretic deposition were used. The feasibility of the DNA-mediated immobilization of NDs was studied using a fluorescent single-stranded DNA (ssDNA) model. We examine and discuss the ND coatings as a future material for implant and drug delivery applications.

\section{Materials and Methods}

Materials and reagents. The pristine NDs employed in this work were purchased from PlasmaChem $\mathrm{GmbH}$, Berlin, Germany. The declared average particle size is $4 \mathrm{~nm}$. Type 1 ultrapure water $\left(\mathrm{ddH}_{2} \mathrm{O}\right)$ was obtained through a Direct-Q 3 UV System water purifier by Merck KGaA (Darmstadt, Germany). Commercially pure (cp) grade 4 Ti was purchased from DOT medical implant solutions $\mathrm{GmbH}$ (Rostock, Germany). The Ti surfaces were cleaned successively using 5 min ultrasound treatment in ethanol, acetone and $\mathrm{ddH}_{2} \mathrm{O}$. The $\mathrm{Si}$ wafers employed in this work were produced by Active Business Company GmbH (Brunnthal, Germany). All Si surfaces were cleaned by boiling 
them for $5 \mathrm{~min}$ in acetone and ethanol; afterwards, they were rinsed with ethanol, and blow-dried using $\mathrm{N}_{2}$. All other chemicals and reagents used in this work were purchased from Merck KGaA (Darmstadt, Germany).

\subsection{De-Agglomeration of Nanodiamonds}

Bead milling was considered to be a de-agglomeration strategy of pristine NDs. Therefore, $0.75 \mathrm{~g}$ of pristine NDs were mixed with $15 \mathrm{~mL}$ of $\mathrm{ddH}_{2} \mathrm{O}$, for a final mass concentration of $50 \mathrm{mg} / \mathrm{mL}$. Then, $7.5 \mathrm{~g}$ of Yttrium-stabilised $\mathrm{ZrO}_{2}$ beads $(100 \mu \mathrm{m}$ diameter by Sigmund Linder $\mathrm{GmbH}$, Warmensteinach, Germany) were added to the suspension as grinding media. The ND slurry was treated with the planetary micro mill Pulverisette 7 from Fritsch GmbH (Idar-Oberstein, Germany). Two consecutive rounds of treatment (700 rpm for $30 \mathrm{~min}$ each) ensured disruption of the ND agglomerates. The suspension was vacuum-filtered using a ceramic filter by Wheaton Inc. (Millville, United States). The volume was increased to $150 \mathrm{~mL}$ by adding $\mathrm{ddH}_{2} \mathrm{O}$ to a final concentration of $5 \mathrm{mg} / \mathrm{mL}$ and the $\mathrm{pH}$ was adjusted to 9.5 by adding $0.1 \mathrm{M} \mathrm{NaOH}$. The slurry was further treated with an ultrasound homogenizer HD 2200 Sonopuls by Bandelin electronic GmbH \& Co. KG (Berlin, Germany), with two 10 -min long cycles at $70 \%$ output power.

\subsection{Colloidal Stability of Nanodiamonds}

Sedimentation rows ranging from $\mathrm{pH} 1$ to $\mathrm{pH} 14$ were prepared by adding either $2 \% \mathrm{H}_{2} \mathrm{SO}_{4}$ or $1 \mathrm{M} \mathrm{NaOH}$. Figure S1 shows each row $24 \mathrm{~h}$ after the preparation of the suspensions. A Delsa Nano Submicron Zetasizer by Beckman Coulter (Brea, CA, United States) was used to measure the particle size distribution and $\zeta$ (zeta) potential. The quartz cuvette with a light path of $1 \mathrm{~cm}$ was purchased from Hellma Analytics (Müllheim, Germany). Each particle size distribution measurement was repeated at least three times. For the zeta potential measurements, the colloids were exposed to a $60 \mathrm{~V}$ potential difference at the extremities of the flow cell, and each suspension was analysed five times. The flow cell and the electrodes were cleaned with $\mathrm{ddH}_{2} \mathrm{O}$, ethanol, and dried under air condition before use.

\subsection{Macroscopic Surface Modification Techniques}

For the dip coating process, the substrates were coated using a KSV Nima Dip Coater by Biolin Scientific Holding AB, Stockholm, Sweden. The samples were immersed in ND suspensions at a speed of $200 \mathrm{~mm} / \mathrm{s}$, left in the suspension for one hour, and withdrawn at a speed of $50 \mathrm{~mm} / \mathrm{s}$. For the electrophoretic deposition (EPD) treatment, the substrates were placed in the suspension and linked to the electric circuit. A platinum sheet electrode by Sensortechnik Meinsberg GmbH (Waldheim, Germany) was used as the counter electrode. The circuit was controlled via an IviumStat impendance analyser (Ivium Technologies B.V., Eindhoven, The Netherlands) in order to define the voltage $(3 \mathrm{~V})$ and the exposure time $(10 \mathrm{~min})$. All samples underwent $\mathrm{O}_{2}$ plasma treatment for 5 min using a Diener electronic Plasmacleaner Femto (Diener GmbH + Co. KG, Ebhausen, Germany). The silanization process took place in an aqueous mixture of $2 \%$ (3-Aminopropyl)triethoxysilane (APTES) with 95\% absolute ethanol solution, which was left to hydrolyse for $10 \mathrm{~min}$. The substrates were placed in the silanization bath and incubated for $4 \mathrm{~h}$. Subsequently, the substrates were washed three times in an absolute ethanol bath and blow-dried with an $\mathrm{N}_{2}$ flow. A final drying stage required baking the substrates in an oven at $120{ }^{\circ} \mathrm{C}$ for $30 \mathrm{~min}$. Carboxylated NDs were bonded to the silanized surface through 1-Ethyl-3-(3-dimethylaminopropyl)carbodiimide and $\mathrm{N}-H y d r o x y s u c c i n i m i d e(E D C / N H S)$-mediated amide formation strategy: equal volumes of the ND suspension and of $100 \mathrm{mM}$ 2-(N-morpholino)ethanesulfonic acid (MES) buffer were mixed, and the silanized substrates were immersed. Afterwards, the coupling took place by adding, dropwise, the first $7.5 \mathrm{mM} \mathrm{EDC}$, and then $7.5 \mathrm{mM} \mathrm{N}$-hydroxysuccinimide (NHS) to reach a total concentration of $4.7 \mathrm{mM}$ each. The substrates were incubated for $20 \mathrm{~min}$ and blow-dried with $\mathrm{N}_{2}$ flow. 


\subsection{Imaging and Analysing}

SEM topography was analysed using a XL30 ESEM by Philips (Amsterdam, Netherlands). Samples were sputter-coated with a 5-nm layer of Au by using a Q300TD sputter coater (Quorum Technologies Ltd., Laughton, United Kingdom), and subsequently imaged with an electron-accelerating voltage of $3 \mathrm{keV}$. The JEOL JEM 1400 plus was used at $120 \mathrm{kV}$ for transmission electron microscopy (TEM) images of ND agglomerates. Atomic force microscopy (AFM) topography information was obtained using Nanowizard II by JPK Instruments (Berlin, Germany) in contact mode, applying Veeco tips $(k=0.1 \mathrm{~N} / \mathrm{m})$. The Ti samples were prepared using SiC P4000 machine polishing prior to the immobilization steps, and scanned in $400 \mu \mathrm{m}^{2}$ arrays. In order to remove unbound NDs, coated samples were immersed for 5 min in $\mathrm{H}_{2} \mathrm{O}$ before AFM and nanoindentation measurements. Fluorescence microscopy was carried out on a Zeiss Axiovert 200M inverted fluorescence microscope using the band-pass Zeiss filter F10 (515 nm-565 nm). $0.5 \mu \mathrm{L}$ droplets of the fluorescently labelled (ssDNA-conjugated) NDs were placed on cleaned microscope glass slides (VWR International LLC, Radnor, Wayne, PA, United States). In order to remove any impurities from the glass surface, samples were cleaned following the acid/base Radio Corporation of America (RCA) cleaning protocol. The slides were placed vertically in a PTFE holder and treated with ultrasound in acetone and in $\mathrm{ddH}_{2} \mathrm{O}$ for 8 min each. After briefly rinsing them with $\mathrm{ddH}_{2} \mathrm{O}$, they were placed for $15 \mathrm{~min}$ in a boiling 5:1:1 solution of $\mathrm{H}_{2} \mathrm{O}: \mathrm{H}_{2} \mathrm{O}_{2}: \mathrm{HCl}$. The slides were rinsed with $\mathrm{ddH}_{2} \mathrm{O}$, then placed for $15 \mathrm{~min}$ in a boiling 5:1:1 solution of $\mathrm{H}_{2} \mathrm{O}: \mathrm{H}_{2} \mathrm{O}_{2}: \mathrm{NH}_{4} \mathrm{OH}$. They were finally rinsed with $\mathrm{ddH}_{2} \mathrm{O}$ and blow-dried with $\mathrm{N}_{2}$. A Hysitron TI950 nano-indenter equipped with a hemispherical diamond tip (radius $=10 \mu \mathrm{m}$ ) produced by Synton MDP AG (Nidau, Switzerland) was employed for nanoindentation measurements. A perpendicular force of $2000 \mu \mathrm{N}$ was exerted, and the probe was dragged along the coated substrates for $20 \mu \mathrm{m}$. During the whole experiment, all tip movements were performed with a constant velocity of $1.5 \mu \mathrm{m} / \mathrm{s}$. For each sample, ten measurements were performed. A distance of $5 \mu \mathrm{m}$ was kept between individual measurements.

\subsection{Functionalisation of Nanodiamonds}

Carboxylated NDs were obtained after wet oxidation of pristine NDs in a 3:1 mixture of $95 \%$ concentrated $\mathrm{H}_{2} \mathrm{SO}_{4}$ with $30 \% \mathrm{H}_{2} \mathrm{O}_{2}$ at $100{ }^{\circ} \mathrm{C}$ for $24 \mathrm{~h}$. Figure S2 shows the FTIR measurements of the pristine and carboxylated NDs taken with an Alpha-P total reflectance spectroscope by Bruker (Billerica, MA, United States). In order to demonstrate the DNA-mediated immobilization strategy, carboxylated ND agglomerates were conjugated with fluorescently labelled ssDNA molecules. The 25-base-pair DNA fragments were purchased from Biomers.net $\mathrm{GmbH}$ (Ulm, Germany) with the following sequence: CGA GAC CTT ATT CCG CAG AGC CTA T ( $5^{\prime}$ to $\left.3^{\prime}\right)$. They present a thiol group on the $5^{\prime}$ terminus, and a fluorescein amidite molecule on the $3^{\prime}$ terminus. Using a dehydration reaction, the ssDNA was bonded covalently to the ND surface by forming a thioester with the carboxylic group. $10 \mathrm{mM}$ phosphate-buffered saline (PBS) buffer was used as solvent. For each conjugation, $1.5 \mathrm{mg}$ of carboxylated NDs were mixed for one hour with the ssDNA, by inverting the solutions. After incubation, the suspensions were centrifuged twice at $5000 \times g$ for $10 \mathrm{~min}$, including an intermediate washing step with $\mathrm{ddH}_{2} \mathrm{O}$.

\section{Results}

Initially, de-agglomerated ND suspensions were obtained using bead milling of the commercialized NDs. The reduction of the ND agglomeration size is a compulsory process to deploy the full potential of these carbon-based nanoparticles. The high surface-to-volume ratio is necessary both for homogeneous coatings and for further efficient functionalization processes. In this work, in-house bead-milled $1 \mathrm{mg} / \mathrm{mL}$ aqueous ND suspensions were employed with a mean hydrodynamic diameter of $43 \pm 2 \mathrm{~nm}$ at $\mathrm{pH}$ 12. See Figure S3 for details regarding the zeta potential and mean agglomerate size of NDs as a function of the ionic strength of the dispersion medium. Figure S4 shows TEM images to confirm ND agglomerate size and individual particle size. The aim of the current study is to investigate the immobilization strategy of NDs as a coating material in combination with metallic 
implant materials. ND coatings for further chemical vapor deposition (CVD) treatments are widely discussed [37-39]. These coatings are based on electrostatic interactions and van der Waals forces of the substrates and NDs. We demonstrate the immobilization of NDs using covalent bonds with higher adhesive properties compared to adhered NDs. The model for the ND immobilization using silanized surfaces is shown in Figure 1.

The covalent immobilized NDs will be compared to physisorbed NDs. In order to achieve a homogenously dense and nanometre-sized ND coating of commercial pure (cp) grade $4 \mathrm{Ti}$, three different coating strategies were studied using topographic investigation methods. Figure 2 shows the SEM and AFM images, including the correlated sample profile. Suitable coating methods were identified, namely dip coating and electrophoretic deposition (EPD) for physisorbed NDs, as well as amide-boned NDs for the covalent immobilization pathway.

APTES

+ oxidized surface

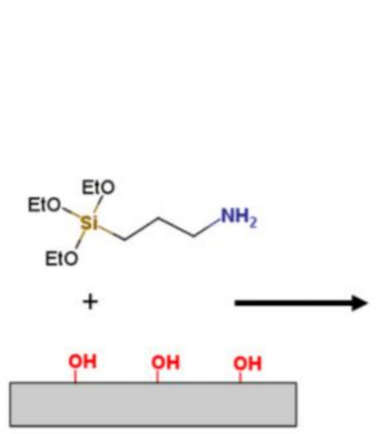

Silanized surface

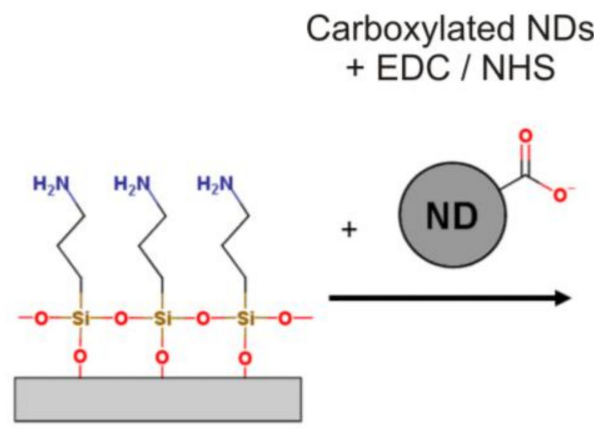

Amide-bonded NDs

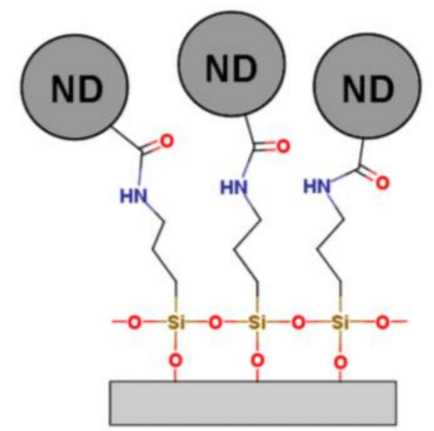

Figure 1. Covalent immobilization using (3-Aminopropyl)triethoxysilane and 1-Ethyl-3-(3-dimethylaminopropyl)carbodiimide and N-Hydroxysuccinimide (EDC/NHS) activation of carboxylated NDs. Modified from [40].

Uncoated
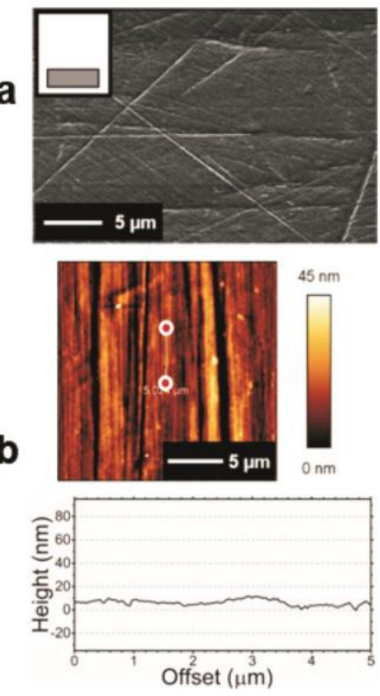

Dip coated
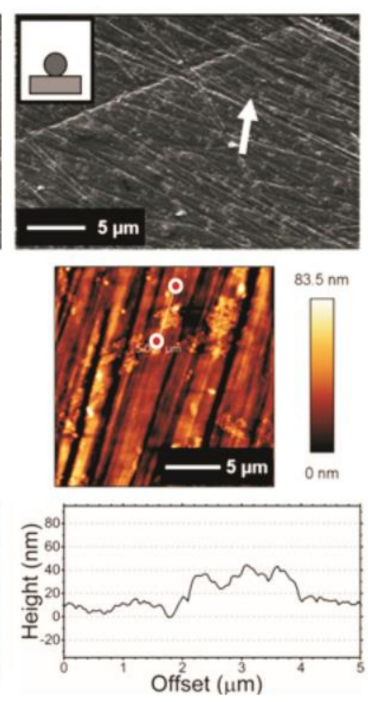

EPD-treated
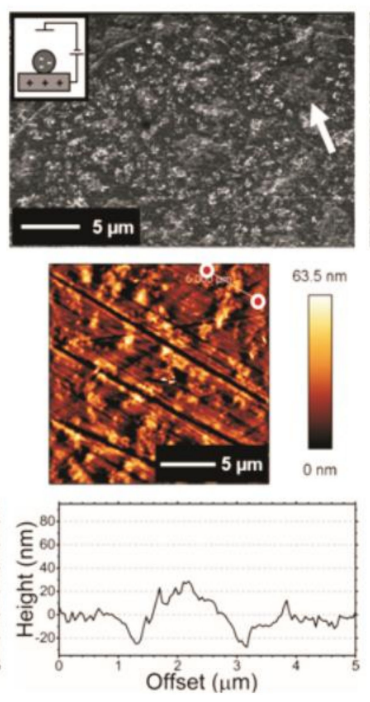

Amide-bonded NDs
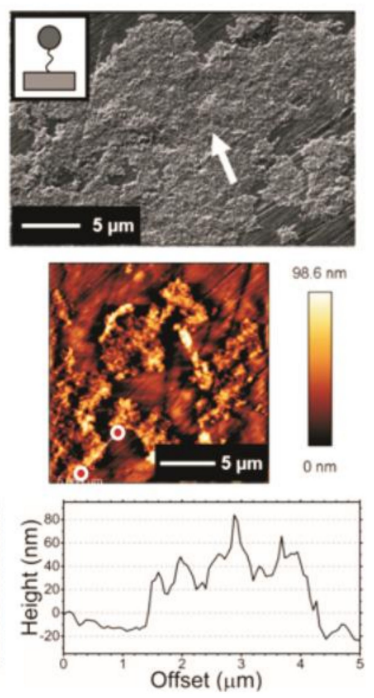

Figure 2. (a) Scanning electron microscopy (SEM) images and (b) atomic force microscopy (AFM) images, including the correlated profile measurements of dip-coated, electrophoretic deposition (EPD)-treated and covalently immobilized nanodiamonds (NDs) on native $\mathrm{TiO}_{2}$, in comparison to the uncoated surface.

The SEM images of the NDs coated onto Ti are shown in Figure 2a. The white arrows mark the ND agglomerates on the Ti surface, and serve as a guide to the eye. Due to the homogenously 
applied electric field, the EPD-treated surfaces display a higher ND density compared to the dip-coated samples. In both cases, electrostatic and van der Waals interactions lead to the loose attachment of the NDs. The highest immobilization rate of NDs is achieved using the formation of amide bridges between silanized surfaces and carboxylated NDs. Figure $2 b$ represents the correlated AFM images. Scratches and inhomogeneities in the AFM images are related to the polishing process and sample roughness. The covalent immobilization strategy requires carboxylated NDs and amine-terminated silanized surfaces. The agglomerates of carboxylated NDs are bigger, due to their higher number of functional carboxylic acid surface groups and intrinsic hydrogen bonding [41]. This explains the $40 \mathrm{~nm}$ height difference in the sample profile of amide-bonded NDs. Table 1 provides the information on surface roughness parameters for uncoated, dip-coated, EPD-treated, and amide-bonded NDs on Ti calculated from Figure $2 b$.

Table 1. Excess surface area, mean deviation (Ra), and the root mean square (RMS) of surface roughness parameters for the uncoated, dip-coated, EPD-treated, and amide-bonded NDs on Ti. Projected area $=$ $400 \mu \mathrm{m}^{2}$.

\begin{tabular}{ccccc}
\hline & Uncoated & Dip Coated & EPD-Treated & Amide-Bonded NDs \\
\hline Excess surface area $\left(\mu \mathrm{m}^{2}\right)$ & 1.0 & 11.7 & 5.5 & 19.6 \\
Ra $(\mathrm{nm})$ & 7.3 & 17.7 & 19.6 & 49.7 \\
RMS $(\mathrm{nm})$ & 10.6 & 24.4 & 25.1 & 66.3 \\
\hline
\end{tabular}

Overall, the covalent, immobilized NDs provide the best results in terms of reproducibility, with homogeneous and almost total surface coverage. In order to qualify the attachment of the immobilized NDs, nanoindentation measurements were carried out on planar Si as reference material, to avoid the influence of the surface inhomogeneities of the employed Ti. Figure 3 illustrates the attachment strength of the NDs to the surface, using the direct determination of the lateral force to move the indentation tip and ND agglomerates, respectively.
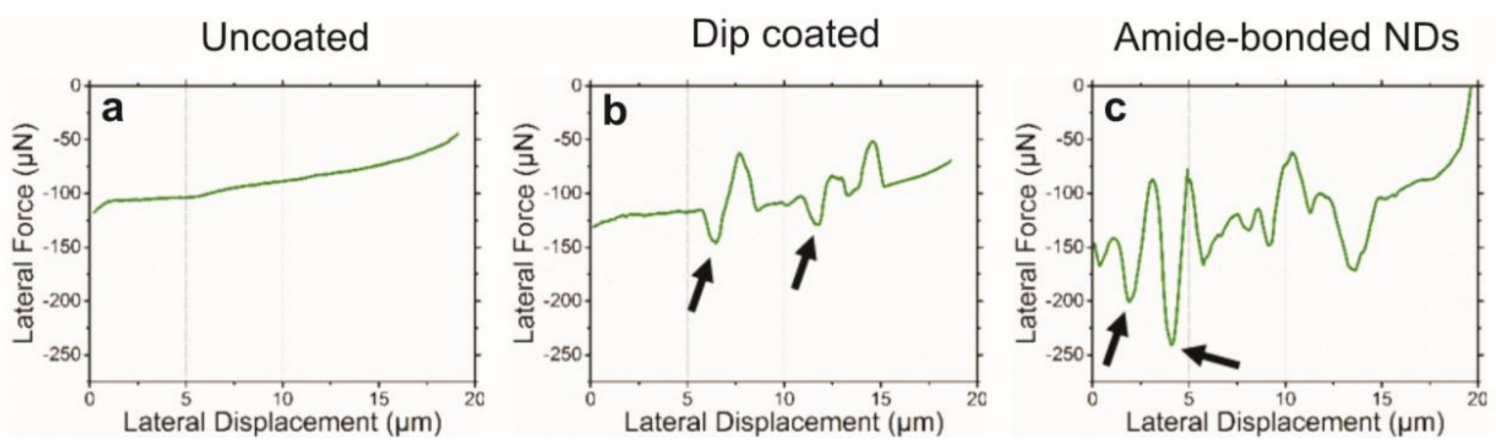

Figure 3. Representative nanoindentation tests of (a) uncoated, (b) dip-coated, and (c) amide-bonded NDs to Si. Graphs show the lateral force as a function of the lateral displacement of the indentation tip.

The measurements in Figure 3 describe the movement of the nanoindentation tip on the surface, and show the lateral force as a function of lateral displacement. Figure 3a demonstrates the measurements for the bare $\mathrm{Si}$ as a reference for the subsequent coatings, whereby Figure S5 displays the SEM images of the corresponding ND-coated Si samples. The lateral force increases following the direction of the tip. For both ND-coated samples, sharp peaks (black arrows Figure 3b,c) in lateral force were detected, with greater variations for the covalently immobilized ND surface than for the dip-coated surface. Intense force jumps were observed during the lateral displacement of the tip, moving along the sample of amide-bonded NDs, where bigger ND agglomerates exert higher forces on the indenter tip. In the resistance of the agglomerates opposing the moving tip, clear differences are observable. Amide-bonded NDs exhibit $60 \%$ higher lateral forces compared to the dip-coated NDs. The ND attachment of dip-coated samples are based on physisorption, mainly caused by weak 
van der Waals force, whereas amide-bonded (chemisorbed) ND agglomerates possess strong amide compounds to the substrate. Every peak in the lateral force is likely to be associated to a single ND agglomerate resisting the movement of the tip. The sharp peaks in lateral force appear as the tip either skips or completely detaches from the same agglomerate. Nanoindentation measurements provide a first means of comparison for the binding strength of differently immobilized ND agglomerates. Comparing the absolute variations of lateral force, the covalently immobilized ND agglomerates pose a higher resistance to the tip movement, confirming that the interaction of NDs with the substrate is stronger than on the dip-coated surface.

Apart from the above-shown immobilization strategies, an alternative covalent immobilization strategy—a DNA-mediated immobilization of NDs to previously ssDNA loaded substrates-will be discussed. We propose biomolecules as linkers of NDs to macroscopic surfaces. Therefore, a facile ssDNA grafting to NDs is required for further hybridization of the immobilized counterparts. Previous attempts to graft functional DNA to NDs have utilized various complex steps. Gaillard et al. [42] used NHS-mediated amide bridges to bind NDs to peptide nuclei acids. Further approaches have focused on chopper-free click reactions with $\mathrm{N}_{3}$-functionalised NDs [43], DNA-biotin-avidin-biotin-ND origami [44], and DNA physisorption to NDs [45]. As an initial step of the proposed model, a facile conjugation of NDs to ssDNA as a platform for further immobilization on macroscopic surfaces is required. Figure 4 shows the results of the conjugation of NDs, using covalent grafting of thiol-terminated ssDNA onto carboxylated NDs through thioester formation (see inset in Figure 4a).

a

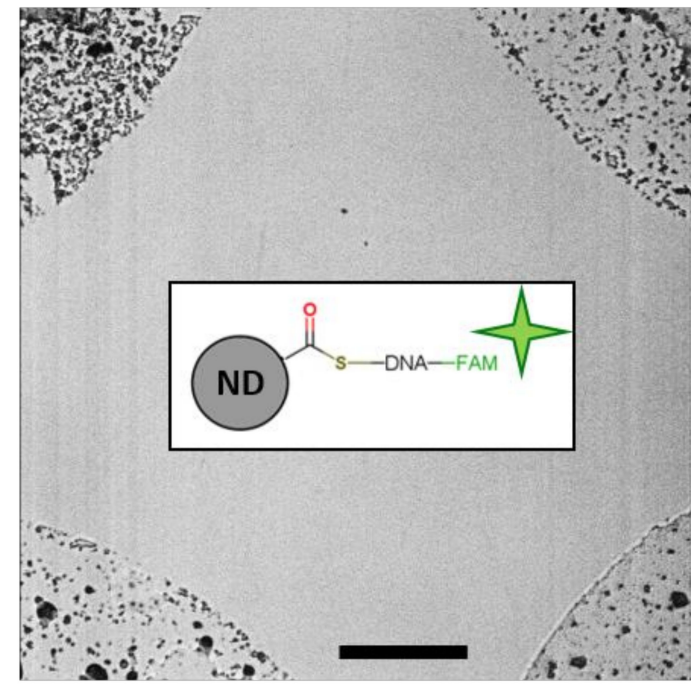

C

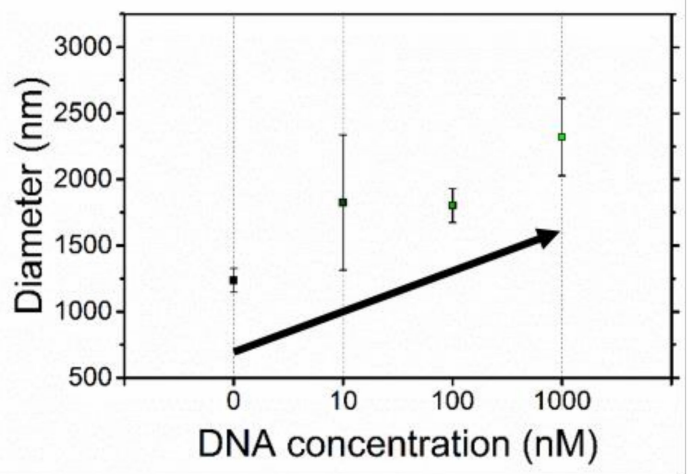

b

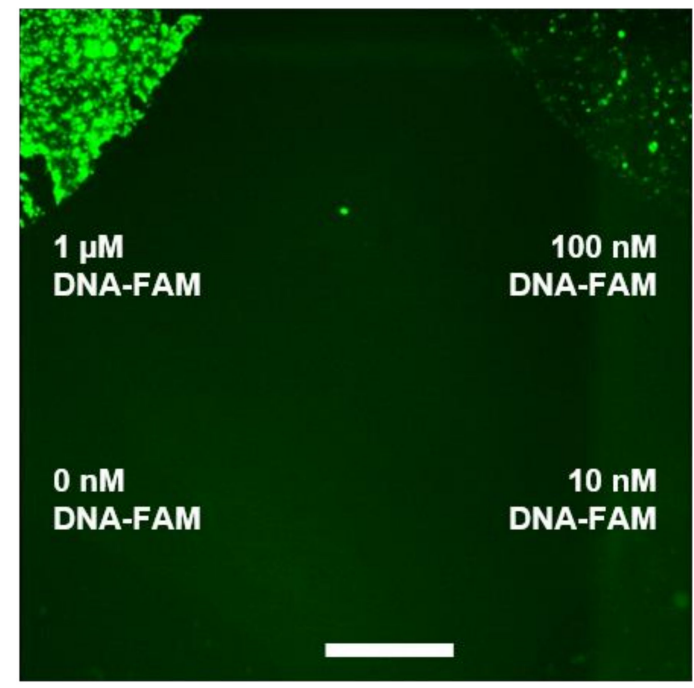

d

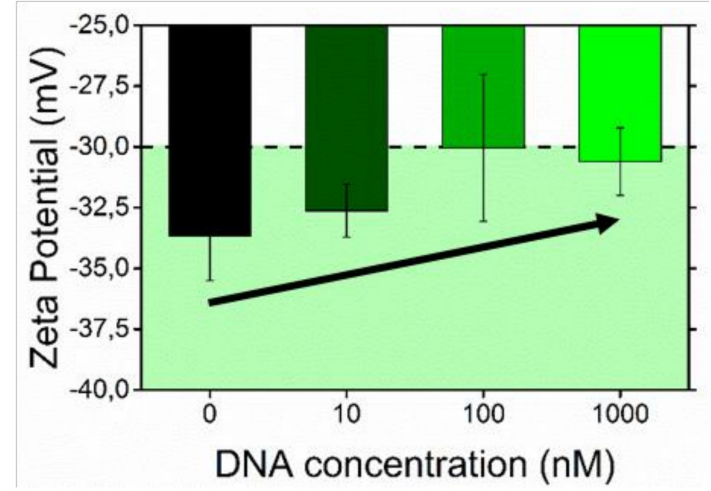

Figure 4. (a) Optical bright-field microscopy image and (b) correlated fluorescent microscopy image of fluorescently labelled ssDNA grafted onto NDs. Scale bar $=50 \mu \mathrm{m}$. (c) Dynamic light scattering and (d) zeta potential measurements of ND/ssDNA conjugates in phosphate-buffered saline (PBS). Concentration of ssDNA range from $0-1000 \mathrm{nM}$. 
The optical and fluorescent microscopy images of ssDNA grafted onto NDs are shown in Figure $4 \mathrm{a}, \mathrm{b}$. The bright-field image confirms the presence of ND agglomerates in the respective droplets. The concentration of the ssDNA in the ND-conjugates, ranging from 0 to $1000 \mathrm{nM}$, is represented in the fluorescent microscopy image. The fluorescent intensity is related proportionally to the ssDNA concentration, which proves the successful conjugation of the NDs. These findings correlate to the agglomerate size distribution and zeta potential measurements displayed in Figure 4c,d. With increasing ssDNA concentration of the ND-conjugates, zeta potential decreases, which leads to an increased mean agglomerate size due to the reduced repulsion and lower amount of available functional surface groups of the NDs. Recently, the drug delivery of NDs using carbodiimide chemistry [46,47] and electrostatic interactions [36] has been discussed. We show the successful binding of ssDNA to carboxylated NDs based on thioester bridges. Further hybridization of the described ssDNA/ND conjugates with complementary DNA probes leads to a cleavable covalent connection between macroscopic surfaces and NDs. The immobilization of phosphate-terminated DNA using anodic anodization as a possible counterpart for the ssDNA/ND conjugates is known from Beutner et al. [48]. Other immobilization techniques of DNA are based on physical adsorption, covalent immobilization, and streptavidin—biotin immobilization [49]. We propose an immobilization model of ssDNA-conjugated NDs with partial entrapped complementary ssDNA counterparts. Introduction of restriction enzymes to such systems implements the possibility of cleaving the hybridized DNA into fragments [50], and consequently releasing the bonded NDs.

\section{Discussion}

This work describes the next step of application-oriented research into NDs with respect to biomedical applications. The objective was to evaluate the combination of scalable coating techniques and the drug-delivery capabilities of NDs. Widely-used biomaterials were coated with NDs by applying dip-coating, electrophoretic deposition, and covalent immobilization, using macroscopic, amine-terminated, silanized surfaces. The pragmatic study of ND coating behaviour and a qualitative assessment using nanoindentation and secondary electron microscopy shows the strongest and densest coating in the case of amide-bonded NDs. APTES will immobilize NDs due to an amide formation, where the covalent bond shows higher adhesive properties compared to the electrostatic and van der Waals interactions of physisorbed NDs. The present study is able to enhance the adhesion properties of immobilized NDs on biopolymer scaffolds. Recently, ND-modified, polymer-based bio-scaffolds are discussed for clinical applications. Yassin et al. showed an increased seeding efficiency of bone marrow stromal cells, due to the nanotopographical features of NDs in copolymer bio-scaffolds [51]. It has been shown that immobilized and protein functionalized NDs have improved in vivo vascularization and bone formation [52]. Oxygen-terminated NDs are an effective design to maximize the biological activity of an implant. Xing et al. proved this concept using NDs as additives in poly(LLA-co-CL) scaffolds [53]. In conclusion, NDs are promising candidates for surface engineering approaches to biomaterials, and this work provides the information on various immobilization techniques. The surface of biomaterials plays a significant role during osseointegration. Immobilized nanoparticles on macroscopic rough surfaces describe a hierarchical structure. Fast in vivo bone formation ability and in vitro functionality of structured surfaces are ascribed to the synergistic effects of a hierarchical hybrid micro/nano-topography, according to Zhang et al. [53]. The macroscopic rough surface, e.g., obtained through sand-blasting, is a recommended substrate for the immobilization of nanoparticles. The successful conjugation of NDs to ssDNA through thioester bridges has been confirmed using fluorescent microscopy, particle size distribution, and zeta potential measurements. These measurements approve thioesters as a valid alternative coupling strategy to the previously discussed EDC/NHS-mediated amide formation. Drug delivery is an immensely complex task. As an initial step for further drug delivery platforms, we provide evidence of facile conjugation steps. Based on our results, we propose a combination of ssDNA-functionalised ND with the partial entrapment of adsorbed nuclei acids on Ti-based materials, for further cleavable immobilization 
strategies for NDs. We expect that it is possible to produce implant surfaces with high wear and infection resistance through the combination of the functionalisation potential with the structural improvements derived from the NDs. The immobilized NDs offer a huge variety of further options to link drug molecules to the implant surface, especially at the critical interface of soft tissue and implant surface. Despite our results, further experiments are required to pass the preclinical trials. In order to use the described immobilization techniques of NDs on metallic implant materials, the osteoblast cell behaviour is recommended for further investigations. The outcomes of the present study prove the concept of covalent immobilization strategies for NDs. Further experiments conducting a combination of electrophoretic deposition of carboxylated NDs and silanized surfaces, as well as biocompatibility tests of the surfaces are recommended. In order to address the translational relevance of ND-based coatings for biomedical applications, environmental $\mathrm{pH}$ and drug adsorption mechanisms should be considered. Both thioester bridges and the proposed DNA-mediated immobilization strategy possess covalent bonds with the NDs, which could decrease the drug binding efficiency of these nanomaterials. Another crucial factor is the mobility and the target delivery of the small biomolecule/ND complexes within biological media. The influence of sterilization processes for the proposed coating models should be verified, including biostability in dynamic environments.

Supplementary Materials: The following are available online at http:/ / www.mdpi.com/2076-3417/9/6/1064/s1, Figure S1 shows the sedimentation row of aqueous ND suspensions at various $\mathrm{pH}$ levels. Figure S2 displays the IR spectroscopy of pristine and carboxylated NDs. Figures S3 and S4 show the particle size distribution and zeta potential, as well as TEM images of NDs, respectively. Figure S5 represents the ND topography employed in the nanoindentation tests.

Author Contributions: N.R.D. and S.B. carried out immobilization and characterization techniques, sedimentation rows, and IR spectra; S.B. contributed to text preparation, prepared supporting information, and Figure 1; B.K. carried out dynamic light scattering (DLS) measurements and TEM imaging; J.S. and G.C. contributed to discussions; L.R. and J.O. contributed to discussions, text preparation, and preparation of Figures 3 and 4 . The manuscript was written through contributions of all authors.

Funding: We gratefully acknowledge the support through the International Excellence Graduate School on Emerging Materials and Processes Korea (iEGSEMP Korea) in the context of TU Dresden's Institutional Strategy, funded by the Excellence Initiative of the German Federal and State Governments. This work was financially supported by the Fraunhofer-Attract project PrimBioCer.

Acknowledgments: The authors would like to thank A. Clausner for his help with nanoindentation. Special thanks to B. Kruppke for his help regarding the SEM, and S. Klinghammer for her support with the fluorescent microscopy.

Conflicts of Interest: The authors declare no conflict of interest. The funders had no role in the design of the study; in the collection, analyses, or interpretation of data; in the writing of the manuscript; or in the decision to publish the results.

\section{References}

1. Niinomi, M. Recent research and development in titanium alloys for biomedical applications and healthcare goods. Sci. Technol. Adv. Mater. 2003, 4, 445-454. [CrossRef]

2. Albrektsson, T.; Brånemark, P.-I.; Hansson, H.-A.; Lindström, J. Osseointegrated Titanium Implants: Requirements for Ensuring a Long-Lasting, Direct Bone-to-Implant Anchorage in Man. Acta Orthop. Scand. 1981, 52, 155-170. [CrossRef] [PubMed]

3. Le Gu'ehennec, L.; Soueidan, A.; Layrolle, P.; Amouriq, Y. Surface treatments of titanium dental implants for rapid osseointegration. Dent. Mater. J. 2007, 23, 844-854. [CrossRef] [PubMed]

4. Liu, X.; Chu, P.K.; Ding, C. Surface modification of titanium, titanium alloys, and related materials for biomedical applications. Mater. Sci. Eng. R Rep. 2004, 47, 49-121. [CrossRef]

5. Diamanti, M.V.; Curto, B.D.; Pedeferri, M. Anodic oxidation of titanium: From technical aspects to biomedical applications. J. Appl. Biomater. Biomech. 2011, 9, 55-69. [CrossRef]

6. LeGeros, R.Z. Properties of Osteoconductive Biomaterials: Calcium Phosphates. Clin. Orthop. Relat. Res. 2002, 395, 81-98. [CrossRef]

7. Hench, L.L. The story of Bioglass. J. Mater. Sci. Mater. Med. 2006, 17, 967-978. [CrossRef]

8. Roy, R.K.; Lee, K.-R. Biomedical Applications of Diamond-Like Carbon Coatings: A Review. J. Biomed. Mater. Res. Part B Appl. Biomater. 2007, 83B, 72-84. [CrossRef] 
9. Chowdhury, S.; Hillman, D.A. Synthesis of ultrasmooth nanostructured diamond films by microwave plasma chemical vapor deposition using a $\mathrm{He} / \mathrm{H}_{2} / \mathrm{CH}_{4} / \mathrm{N}_{2}$ gas mixture. J. Mater. Res. 2006, 21, $2675-2682$. [CrossRef]

10. Yang, L.; Jiang, C.; Guo, S. Novel Diamond Films Synthesis Strategy: Methanol and Argon Atmosphere by Microwave Plasma CVD Method Without Hydrogen. Nanoscale Res. Lett. 2016, 11, 415. [CrossRef]

11. Wang, H.-D.; Yang, Q.; Niu, C.H. Preparation of films of nanodiamonds by step-by-step deposition approach through hydrogen bonding. Diam. Relat. Mater. 2012, 25, 73-79. [CrossRef]

12. Forsgren, J.; Engqvist, H. A novel method for local administration of strontium from implant surfaces. J. Mater. Sci. Mater. Med. 2010, 21, 1605-1609. [CrossRef] [PubMed]

13. Mertens, C.; Steveling, H.G. Early and immediate loading of titanium implants with fluoride-modified surfaces: Results of 5-year prospective study. Clin. Oral Implants Res. 2011, 22, 1354-1360. [CrossRef] [PubMed]

14. Ostman, P.O.; Wennerberg, A.; Ekestubbe, A.; Albrektsson, T. Immediate occlusal loading of NanoTiteTM tapered implants: A prospective 1-year clinical and radiographic study. Clin. Implant Dent. Relat. Res. 2013, 15, 809-818. [CrossRef] [PubMed]

15. Pistilli, R.; Felice, P.; Piattelli, M.; Gessaroli, M.; Soardi, E.; Barausse, C.; Buti, J.; Corvino, V. Posterior atrophic jaws rehabilitated with prostheses supported by $5 \times 5 \mathrm{~mm}$ implants with a novel nanostructured calciumincorporated titanium surface or by longer implants in augmented bone: One-year results from a randomized controlled trial. Eur. J. Oral Implantol. 2013, 6, 343-357. [PubMed]

16. Kim, H.-S.; Kim, Y.-J.; Jang, J.-H.; Park, J.-W. Surface Engineering of Nanostructured Titanium Implants with Bioactive Ions. J. Dent. Res. 2016, 95, 558-565. [CrossRef]

17. Li, B.; Li, Y.; Li, J.; Fu, X. Improvement of biological properties of titanium by anodic oxidation and ultraviolet irradiation. Appl. Surf. Sci. 2014, 307, 202-208. [CrossRef]

18. Portan, D.V.; Kroustalli, A.A.; Deligianni, D.D.; Papanicolaou, G.C. On the biocompatibility between $\mathrm{TiO} 2$ nanotubes layer and human osteoblasts. J. Biomed. Mater. Res. 2012, 100A, 2546-2553. [CrossRef]

19. Voznyakovskii, A.P.; Shugalei, I.V. Surface Characterization of Detonation Nanodiamond Particles. Russ. J. Gen. Chem. 2012, 82, 2256-2258. [CrossRef]

20. Mochalin, V.N.; Shenderova, O.; Ho, D.; Gogotsi, Y. The properties and applications of nanodiamonds. Nat. Nanotechnol. 2011, 7, 11-23. [CrossRef]

21. Liu, K.-K.; Cheng, C.-L.; Chang, C.-C.; Chao, J.-I. Biocompatible and detectable carboxylated nanodiamond on human cell. Nanotechnology 2007, 18, 325102. [CrossRef]

22. Ho, D.; Wang, C.-H.K.; Chow, E.K.-H. Nanodiamonds: The intersection of nanotechnology, drug development, and personalized medicine. Sci. Adv. 2015, 1, e1500439. [CrossRef]

23. Chow, E.K.; Zhang, X.-Q.; Chen, M.; Lam, R.; Robinson, E.; Huang, H.; Schaffer, D.; Osawa, E.; Goga, A.; Ho, D. Nanodiamond Therapeutic Delivery Agents Mediate Enhanced Chemoresistant Tumor Treatment. Sci. Transl. Med. 2011, 3, 73ra21. [CrossRef]

24. Schrand, A.M.; Huang, H.; Carlson, C.; Schlager, J.J. Are Diamond Nanoparticles Cytotoxic? J. Phys. Chem. B 2007, 111, 2-7. [CrossRef]

25. Chao, J.-I.; Perevedentseva, E.; Chung, P.-H.; Liu, K.-K. Nanometer-Sized Diamond Particle as a Probe for Biolabeling. Biophys. J. 2007, 93, 2199-2208. [CrossRef]

26. El-Say, K.M. Nanodiamond as a drug delivery system: Applications and prospective. J. Appl. Pharm. Sci. 2012, 1, 29-39.

27. Vial, S.; Mansuy, C.; Sagan, S.; Irinopoulou, T.; Burlina, F.; Boudou, J.-P.; Chassaing, G.; Lavielle, S. Peptide-Grafted Nanodiamonds: Preparation, Cytotoxicity and Uptake in Cells. ChemBioChem 2008, 9, 2113-2119. [CrossRef]

28. Puzyr, A.P.; Baron, A.V.; Purtov, K.V.; Bortnikov, E.V. Nanodiamonds with novel properties: A biological study. Diam. Relat. Mater. 2007, 16, 2124-2128. [CrossRef]

29. Bradac, C.; Say, J.M.; Rastogi, I.D.; Cordina, N.M. Nano-assembly of nanodiamonds by conjugation to actin filaments. J. Biophotonics 2016, 9, 296-304. [CrossRef] [PubMed]

30. Yeap, W.S.; Tan, Y.Y.; Loh, K.P. Using Detonation Nanodiamond for the Specific Capture of Glycoproteins. Anal. Chem. 2008, 80, 4659-4665. [CrossRef] 
31. Hens, S.C.; Cunningham, G.; Tyler, T.; Moseenkov, S.; Kuznetsov, V.; Shenderova, O. Nanodiamond bioconjugate probes and their collection by electrophoresis. Diam. Relat. Mater. 2008, 17, 1858-1866. [CrossRef]

32. Wierzbicki, M.; Sawosz, E.; Grodzik, M.; Hotowy, A. Carbon nanoparticles downregulate expression of basic fibroblast growth factor in the heart during embryogenesis. Int. J. Nanomed. 2013, 8, 3427-3435.

33. Thomas, V.; Halloran, B. In vitro studies on the effect of particle size on macrophage responses to nanodiamond wear debris. Acta Biomater. 2012, 8, 1939-1947. [CrossRef] [PubMed]

34. Taylor, A.C.; González, C.H.; Miller, B.S.; Edgington, R.J.; Ferretti, P.; Jackman, R.B. Surface functionalisation of nanodiamonds for human neural stem cell adhesion and proliferation. Sci. Rep. 2017, 7, 7307. [CrossRef] [PubMed]

35. Edgington, R.J.; Thalhammer, A.; Welch, J.O.; Bongrain, A.; Bergonzo, P.; Scorsone, E.; Jackman, R.B.; Schoepfer, R. Patterned neuronal networks using nanodiamonds and the effect of varying nanodiamond properties on neuronal adhesion and outgrowth. J. Neural Eng. 2013, 10, 056022. [CrossRef]

36. Huang, H.; Pierstorff, E.; Osawa, E.; Ho, D. Protein-Mediated Assembly of Nanodiamond Hydrogels into a Biocompatible and Biofunctional Multilayer Nanofilm. ACS Nano 2008, 2, 203-212. [CrossRef] [PubMed]

37. Stehlik, S.; Varga, M.; Stenclova, P.; Ondic, L.; Ledinsky, M.; Pangrac, J.; Vanek, O.; Lipov, J.; Kromka, A.; Rezek, B. Ultrathin Nanocrystalline Diamond Films with Silicon Vacancy Color Centers via Seeding by $2 \mathrm{~nm}$ Detonation Nanodiamonds. ACS Appl. Mater. Interfaces 2017, 9, 38842-38853. [CrossRef]

38. Domonkos, M.; Ižák, T.; Varga, M.; Potocký, Š.; Demo, P.; Kromka, A. Diamond nucleation and growth on horizontally and vertically aligned Si substrates at low pressure in a linear antenna microwave plasma system. Diam. Relat. Mater. 2018, 82, 41-49. [CrossRef]

39. Majchrowicz, D.; Kosowska, M.; Sankaran, K.J.; Struk, P.; Wasowicz, M.; Sobaszek, M.; Haenen, K.; Jedrzejewska-Szczerska, M. Nitrogen-Doped Diamond Film for Optical Investigation of Hemoglobin Concentration. Materials 2018, 11, 109. [CrossRef]

40. Shavel, A.; Gaponik, N.; Eychmueller, A. Covalent Linking of CdTe Nanocrystals to Amino-Functionalized Surfaces. ChemPhysChem 2005, 6, 449-451. [CrossRef]

41. Krüger, A.; Kataoka, F.; Ozawa, M.; Fujino, T.; Suzukic, Y.; Aleksenskii, A.E.; YaVul', A.; Ōsawa, E. Unusually tight aggregation in detonation nanodiamond: Identification and disintegration. Carbon 2005, 43, 1722. [CrossRef]

42. Gaillard, C.; Girard, H.A.; Falck, C.; Paget, V.; Simic, V.; Ugolin, N.; Bergonzo, P.; Chevillard, S.; Arnault, J.C. Peptide nucleic acid-nanodiamonds: Covalent and stable conjugates for DNA targeting. RSC Adv. 2014, 4, 3566. [CrossRef]

43. Akiel, R.D.; Zhang, X.; Abeywardana, C.; Stepanov, V.; Qin, P.Z.; Takahashi, S. Investigating Functional DNA Grafted on Nanodiamond Surface Using Site-Directed Spin Labeling and Electron Paramagnetic Resonance Spectroscopy. J. Phys. Chem. B 2016, 120, 4003-4008. [CrossRef]

44. Zhang, T.; Neumann, A.; Lindlau, J.; Wu, Y.; Pramanik, G.; Naydenov, B.; Jelezko, F.; Schueder, F.; Huber, S.; Huber, M.; et al. DNA-Based Self-Assembly of Fluorescent Nanodiamonds. J. Am. Chem. Soc. 2015, 137, 9776-9779. [CrossRef]

45. Purtov, K.V.; Burakova, L.P.; Puzyr, A.P.; Bondar, V.S. The interaction of linear and ring forms of DNA molecules with nanodiamonds synthesized by detonation. Nanotechnology 2008, 19, 325101. [CrossRef]

46. Basu, R.; Skaggs, N.; Shalov, S.; Brereton, P. Evidence of nanodiamond-self-assembly in a liquid crystal, and the consequent impacts on the liquid crystal properties. AIP Adv. 2017, 7, 075008. [CrossRef]

47. Ryu, T.-K.; Baek, S.W.; Lee, G.-J.; Rhee, C.; Choi, S.-W. Targeted Tumor Therapy Based on Nanodiamonds Decorated with Doxorubicin and Folic Acid. Macromol. Biosci. 2017, 17, 1600180. [CrossRef]

48. Beutner, R.; Michael, J.; Schwenzer, B.; Scharnweber, D. Biological nano-functionalization of titanium-based biomaterial surfaces: A flexible toolbox. J. R. Soc. Interface 2010, 7, 93-105. [CrossRef]

49. Balasaheb Nimse, S.; Song, K.; Sonawane, M.D.; Sayyed, D.R.; Kim, T. Immobilization Techniques for Microarray: Challenges and Applications. Sensors 2014, 14, 22208-22229. [CrossRef]

50. Hu, Q.; Katti, P.S.; Gu, Z. Enzyme-Responsive Nanomaterials for Controlled Drug Delivery. Nanoscale 2014, 6, 12273-12286. [CrossRef] 
51. Yassin, M.A.; Mustafa, K.; Xing, Z.; Sun, Y.; Fasmer, K.E.; Waag, T.; Krueger, A.; Steinmüller-Nethl, D.; Finne-Wistrand, A.; Leknes, K.N. A Copolymer Scaffold Functionalized with Nanodiamond Particles Enhances Osteogenic Metabolic Activity and Bone Regeneration. Macromol. Biosci. 2017, 17, 1600427. [CrossRef] [PubMed]

52. Wu, X.; Bruschi, M.; Waag, T.; Schweeberg, S.; Tian, Y.; Meinhardt, T.; Stigler, R.; Larsson, K.; Funk, M.; Steinmueller-Nethl, D; et al. Functionalization of bone implants with nanodiamond particles and angiopoietin-1 to improve vascularization and bone regeneration. J. Mater. Chem. B 2017, 5, 6629-6636. [CrossRef]

53. Zhanga, W.; Wang, G.; Liu, Y.; Zhao, X.; Zou, D.; Zhu, C.; Jin, Y.; Huang, Q.; Sun, J.; Liu, X.; et al. The synergistic effect of hierarchical micro/nano-topography and bioactive ions for enhanced osseointegration. Biomaterials 2013, 34, 3184-3195. [CrossRef] [PubMed]

2019 by the authors. Licensee MDPI, Basel, Switzerland. This article is an open access article distributed under the terms and conditions of the Creative Commons Attribution (CC BY) license (http:/ / creativecommons.org/licenses/by/4.0/). 